\title{
Decarboxylative Alkynylation and Cyanation of Carboxylic Acids using Photoredox Catalysis and Hypervalent lodine Reagents
}

\author{
Franck Le Vaillant ${ }^{\S}$ and Jérôme Waser ${ }^{\star}$ \\ §SCS-DSM Award for best poster presentation in Organic Chemistry
}

\begin{abstract}
Alkynes and nitriles are important functional groups that serve as versatile building blocks in organic synthesis and find applications in material and medicinal sciences. A convenient and straightforward access to both classes of compounds under mild conditions is, therefore, highly desirable. Herein, we disclose the decarboxylative alkynylation and cyanation of broadly available carboxylic acids using photoredox catalysis and hypervalent iodine reagents. Choices of both catalysts and reagents were crucial. Computational and experimental studies revealed two different possible mechanisms that are dictated by the oxidation potential of the reagents: radical for alkynylation, ionic for cyanation.
\end{abstract}

Keywords: Decarboxylative alkynylation · Decarboxylative cyanation · Mechanistic studies · Hypervalent iodine reagent $\cdot$ Photoredox catalysis

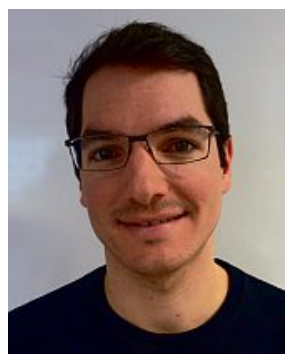

Franck Le Vaillant was born and raised in France. He studied chemistry at the Ecole Nationale Supérieure de Chimie de Montpellier (ENSCM, France). He then moved to Stanford University (USA) where he joined the Trost group as a visiting student researcher, working on a unique intramolecular palladium-catalyzed alkynealkyne coupling to generate strained macrobicyclic enynes. Since November 2014, he started his PhD studies at the Ecole Polytechnique Fédérale de Lausanne (EPFL, Switzerland) in the group of Prof. Jerome Waser. His current research topic involves hypervalent iodine reagents and photoredox catalysis.

${ }^{\star}$ Correspondence: Prof. Dr. J. Waser Laboratory of Catalysis and Organic Synthesis Ecole Polytechnique Fédérale de Lausanne EPFL SB ISIC LCSO, BCH 4306

$\mathrm{CH}-1015$ Lausanne

E-mail: jerome.waser@epfl.ch
The chemistry surrounding alkynes and nitriles is extraordinary rich and useful. ${ }^{[1,2]}$ In particular, aliphatic alkynes or nitriles have a considerable potential as building blocks in organic synthesis and are also broadly applicable to many other areas of chemistry, ranging from pharmaceutical and medicinal sciences to material sciences. ${ }^{[3]}$ As a result the synthesis of these compounds is extremely valuable. The introduction of these two moieties usually takes advantage of the acidity of the sp orbitals, leading to acetylide and cyanide nucleophilic substitutions or additions to an electrophilic center. ${ }^{[1,2,4]}$ Nevertheless, in some substrates, disconnections using this innate reactivity are difficult. In this case, the polarity of the functional group must be reversed (umpolung), which Seebach showed is a useful and efficient concept. ${ }^{[5]}$ In this regard, hypervalent iodine reagents are of considerable interest because they allow the umpolung of many functional groups, such as alkyne and nitrile. Cyclic versions of hypervalent iodine reagents, EthynylBenziodoXolone (EBX) and CyanoBenziodoXolone (CBX), first made by Ochiai ${ }^{[6]}$ and Zhdankin, ${ }^{[7]}$ have been developed and are now broadly used. ${ }^{[8]}$ These reagents, in particular EBX reagents, have also demonstrated great potential for functionalizing carbon-centered radicals. ${ }^{[76,9]}$ As many difficult alkynylation and cyanation reactions occur at high temperature or require transition metal catalysis, ${ }^{[4]}$ an elegant way of achieving non favorable alkynylations and cyanations would be to merge hypervalent iodine reagents and visible light induced photoredox catalysis (Scheme 1). Indeed, photoredox is a topic of growing interest, especially for generating radicals with excellent chemo-selectivity under mild conditions. ${ }^{[10]}$ As traceless activating group and broadly available substrates, carboxylic acids are a particularly attractive class of radical precursors. Furthermore, their decarboxylation under photoredox conditions has already been reported. ${ }^{[11]}$ Introducing an alkyne ${ }^{[9 a, 12]}$ or a nitrile ${ }^{[13]}$ from a carboxylic acid requires several steps using established methods. Therefore a one-step decarboxylative alkynylation or cyanation under mild conditions would provide a faster access. Herein, we report the visible light photoredox mediated decarboxylative alkynylation and cyanation of carboxylic acids using EBX and $\mathrm{CBX}$ reagents.

In 2015, we began investigating the photoredox-mediated decarboxylative alkynylation of aliphatic carboxylic acids using EBX reagents. ${ }^{[14]} \mathrm{N}-\mathrm{Cbz}$ protected proline 4a was used as model substrate to optimize the reaction (Scheme 2). Silylprotected alkynes are synthetically very useful, due to the easily removable protecting group that gives the most versatile terminal alkynes. In that regard, we focused our efforts on optimizing the transfer of TIPS-protected alkyne. Using blue LEDs as light source, we were delighted to isolate $92 \%$ yield of the alkynylated product 


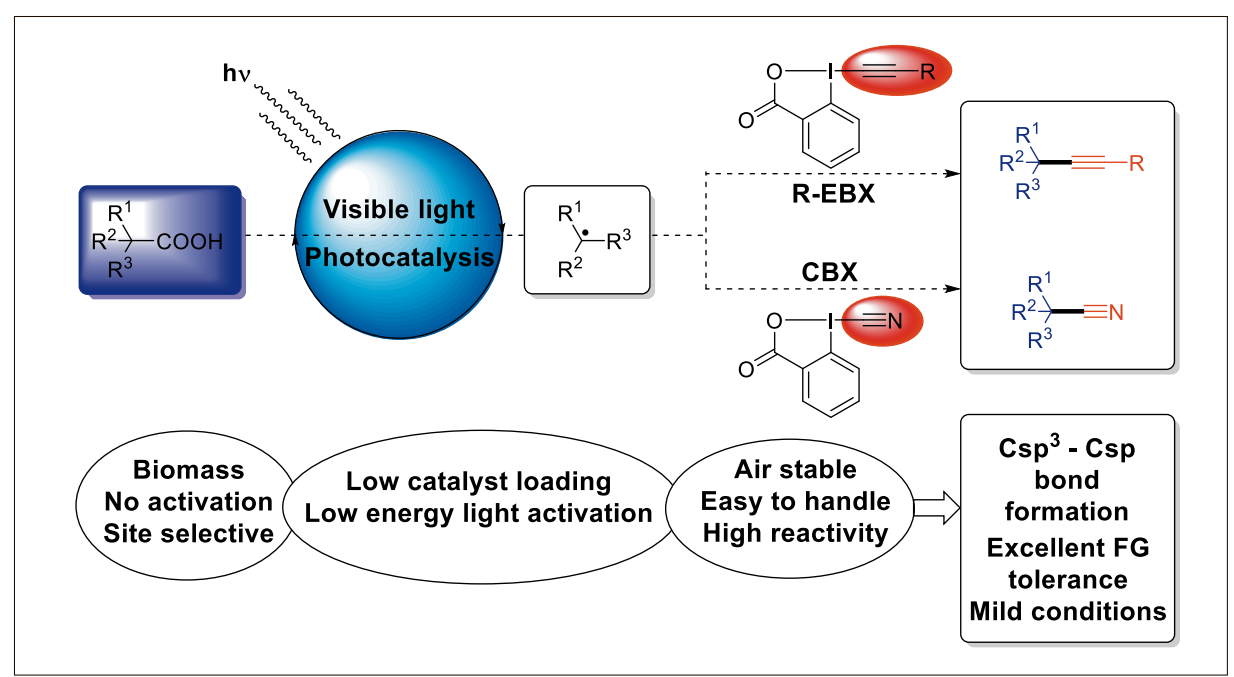

Scheme 1. Our strategy for the decarboxylative alkynylation and cyanation of carboxylic acids.

5a after only $5 \mathrm{~h}$ of irradiation using 1.5 equiv. of TIPS-EBX (1), 3 equiv. of cesium benzoate and $1.0 \mathrm{~mol} \%$ of photocatalyst $\operatorname{Ir}\left(\mathrm{dF}\left(\mathrm{CF}_{3}\right) \mathrm{ppy}_{2}\right) \mathrm{dtbbpyPF}_{6}(3)$ in a $0.2 \mathrm{M}$ DCE solution. Screening various bases showed the superiority of cesium salts, especially cesium carboxylates. Fluorinated phenylpyridinato ligands (C-N ligands) for the iridium-based photocatalyst were found to be crucial for the reaction, while the classic $\mathrm{Ru}(\mathrm{bpy})_{3} \mathrm{Cl}_{2}$ and $f a c-\operatorname{Ir}(\mathrm{ppy})_{3}$ catalysts were unsuccessful for this transformation. ${ }^{[15]}$

Encouraged by this newly developed alkynylation, we wondered if another type of $\mathrm{Csp}^{3}$-Csp coupling could be achieved under similar photoredox conditions. This led to our investigation of decarboxylative cyanation (Scheme 2). ${ }^{[16]}$ After optimization (Scheme 2), substrate $4 \mathbf{a}$ was successfully converted into the corresponding nitrile 6a after $4.5 \mathrm{~h}$ of blue LED irradiation using 1.5 equiv. of CBX reagent 2 as a cyanide source and $1 \mathrm{~mol} \%$ of photocatalyst 3. THF was found to be the best solvent. Molecular sieves were important to avoid the formation of the hemiaminal side product 7 , which we postulate was gener-

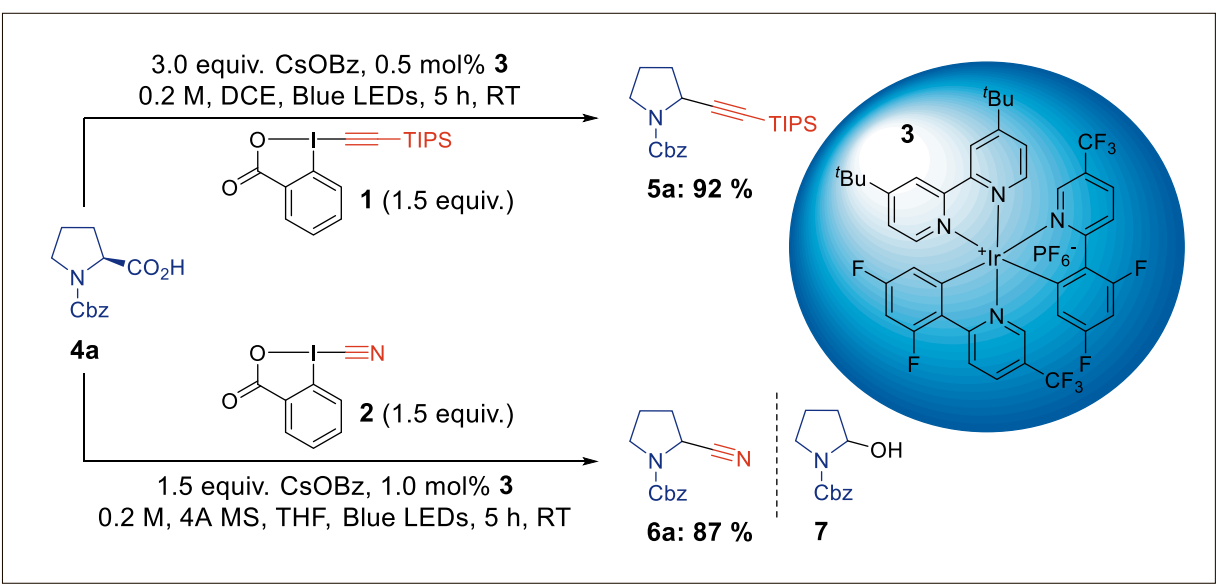

Scheme 2. Optimized conditions for the decarboxylative alkynylation and cyanation. were not successful in this transformation.

We then started to explore the scope (Fig. 2) of both reactions. Both $\mathrm{Cbz}$ and Boc proline were converted into alkynes $\mathbf{5 a}$ and $\mathbf{5 b}$ in $90 \%$ yield at $0.3 \mathrm{mmol}$ scale. Tetrahydroquinoline $\mathbf{5 c}$ was isolated in $87 \%$ yield as a single regioisomer. $\alpha$-Oxy acids were also suitable, as shown by the conversion of tetrahydropyran2-carboxylic acid and THF-2-carboxylic acid to $\mathbf{5 d}(60 \%$ yield) and $\mathbf{5 e}$ (quantitative). Hydrocarbon carboxylic acids are more difficult to functionalize because of the higher oxidation potential of the corresponding carboxylate, ${ }^{[17]}$ and we were pleased to find that adamantane carboxylic acid was smoothly converted to alkyne $\mathbf{5 f}$ in the presence of $2 \mathrm{~mol} \%$ of photocatalyst. Cyclopentane carboxylic acid yielded $\mathbf{5 g}(64 \%)$ under the same conditions. The scope of reagents was also broad and we found that silyl- $(\mathbf{5 h}, 78 \%)$, aryl$(\mathbf{5 i}, 88 \%)$ and alkyl- (5j, 77\%) substituted alkynes could be transferred. Finally, natural light can also promote the reaction without any loss of yield $(89 \%)$ and the product can be easily converted to triazole $\mathbf{8}$ after TBAF deprotection followed by Huisgen 1,3 dipolar cycloaddition with benzyl azide.

We then turned our attention to the scope of cyanation (Fig. 3). It was broader for amino acids (15 examples) than the alkynylation reaction. Various carbamate protecting groups could be used $(\mathbf{6 a}-\mathbf{6 c}$, 86-92\%), but also an electron-rich benzyl protecting group is suitable for this transformation $(\mathbf{6 d}, 43 \%)$. Free alcohols are tolerated, as $\mathbf{6 e}$ was isolated in $90 \%$ yield. In addition to proline derivatives, piperidine and tetrahydroquinoline derivatives are also well suited for this cyanation $(\mathbf{6 f}, \mathbf{6 g}$, $72 \%, 65 \%$ respectively). N-Cbz-protected lysine was converted to the corresponding nitrile $\mathbf{6 h}$ in $83 \%$ yield. Primary, secondary and tertiary radicals are all reactive towards CBX, leading for example to $\mathbf{6 i}(66 \%), \mathbf{6} \mathbf{j}$ $(86 \%), \mathbf{6 k}(49 \%)$. Different substituents are tolerated in the $\alpha$ position of the radical, as shown with valine derivative $\mathbf{6 l}(80 \%)$ or methionine derivative $6 \mathrm{~m}(66 \%)$. We were pleased to find out that dipeptides $(\mathbf{6 n}, \mathbf{6 0}$, $56 \%, 55 \%$ respectively) and $\alpha$-oxy-acids $(\mathbf{6 p}, \mathbf{6 q}, 70 \%, 66 \%$ respectively) were also suitable substrates for cyanation. However, thio-acids did not lead to any nitrile product, likely because of their ability to be easily oxidized. Hydrocarbon aliphatic acids were not transformed well $(<20 \%)$, yielding mostly the corresponding anhydrides (along with mixed anhydrides formed with cesium benzoate). Some valuable intermediates in drug syntheses (Vildagliptin, Idazoxan) can also be synthesized using our new transformation. ${ }^{[16,18,19]}$ The catalyst loading can be decreased, as only 0.1 mol\% of photocatalyst 3 was required to 
obtain $0.60 \mathrm{mmol}$ of the expected nitrile $\mathbf{6 a}$ ( $1 \mathrm{mmol}$ scale, $60 \%$ yield, $48 \mathrm{~h}$ ), meaning a turnover of 600 . Furthermore, this photoredox-mediated cyanation can be promoted by sunlight in only $4 \mathrm{~h}$ irradiation $(90 \%)$.

Comparing the two reactions reveals that photocatalyst $\mathbf{3}$ can be used in both cases $^{[20]}$ and the best structure of the hypervalent iodine reagent is the most simple benziodoxolone core. However, broader scope for amino acids is obtained in the cyanation reaction, along with a lower reactivity in the case of acids not stabilized by a heteroatom in the $\alpha$ position. Another difference is the formation of hemiaminal side product 7, which was suppressed using molecular sieves in the cyanation reaction, whereas this side product was not observed in the alkynylation. These results led us to wonder if the two described reactions might follow two divergent mechanistic pathways. For these two $\mathrm{Csp}^{3}-\mathrm{Csp}$ couplings, a similar mechanism based on the reactivity of the triple bond towards C-centered radicals (Scheme 3, section a) could be envisioned. In the seminal work of $\mathrm{Li}$ on silver-catalyzed decarboxylative alkynylation, ${ }^{[9 a]}$ the proposed mechanism involved $\alpha$-addition of the $\mathrm{C}$-centered radical (intermediate B) to the EBX reagents, followed by $\beta$-elimination leading to the expected alkyne product. To the best of our knowledge, no detailed mechanistic studies have been carried out to support this mechanism. Therefore, we started exploring the mechanism of both transformations, computationally ${ }^{[21]}$ and experimentally. It was found that the decarboxylative alkynylation and cyanation most likely proceed through divergent mechanisms. The photocatalytic cycle is identical ( $\operatorname{Ir}^{\mathrm{III}} \mathbf{3}$ and $\mathbf{3}^{*}$, and $\operatorname{Ir}^{\mathrm{II}} 3^{\text {red }}$ as catalytic species), involving the same cesium carboxylate $\mathbf{A}$ as the first quencher. Indeed, Stern-Volmer studies showed that $\mathbf{A}$ is an excellent quencher of $3^{*}$, while no quenching was observed with CBX. ${ }^{[16,22]}$ Because of the high reactivity of the possible intermediates, DFT computations were undertaken for the alkynylation. The commonly proposed intermediate $\mathbf{a}_{1}$ obtained after $\alpha$-addition was not located, thus excluding this pathway. As hypervalent iodine reagents are known to be oxidants, a single electron transfer between TIPS-EBX and the $\alpha$-amino radical B was also calculated, and appeared feasible (11.3 kcal/mol, Table 1$)$. However the collapse of radical anion intermediate $\mathbf{d}_{1}$ into the acetylide and carboxyl radical $\mathbf{C}$ is highly disfavored $(32.8 \mathrm{kcal} / \mathrm{mol})$. Finally, alkyne transfer happens via a 3-center transition state involving the iodine atom. It could involve the carbon in the $\alpha$ position, leading to a concerted mechanism with a transition state $\mathbf{b}_{\mathrm{TS}}(17.2 \mathrm{kcal} / \mathrm{mol})$ or the carbon in the $\beta$ position (transition state $\mathbf{c}_{\mathrm{TS}} 16.8 \mathrm{kcal} / \mathrm{mol}$ ), both pathways could

\section{Alkynylating reagents}

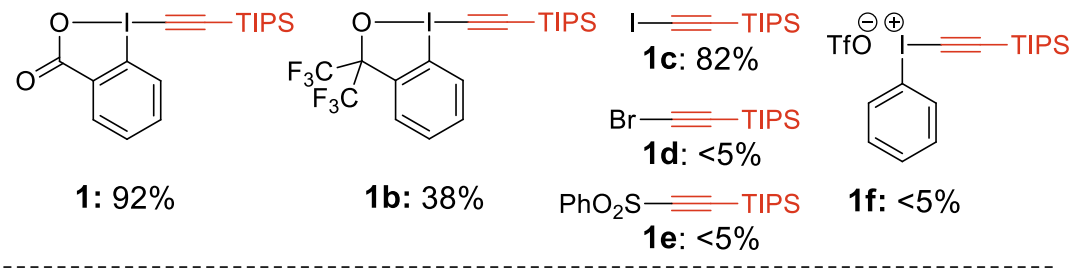

\section{Cyanating reagents}

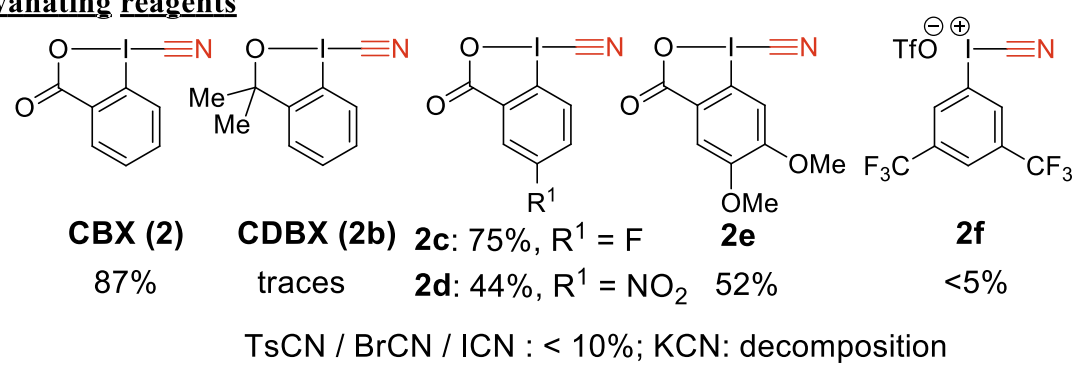

Fig. 1. Screening of alkynylating and cyanating reagents.

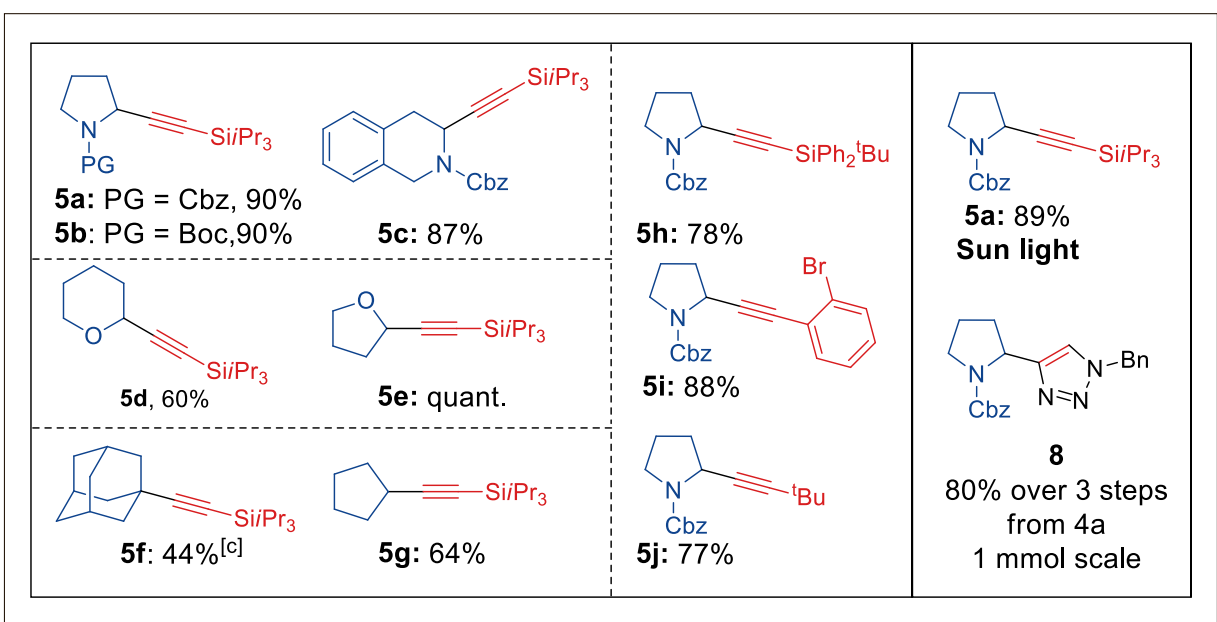

Fig. 2. Selected examples of the scope of the photoredox catalyzed decarboxylative alkynylation.

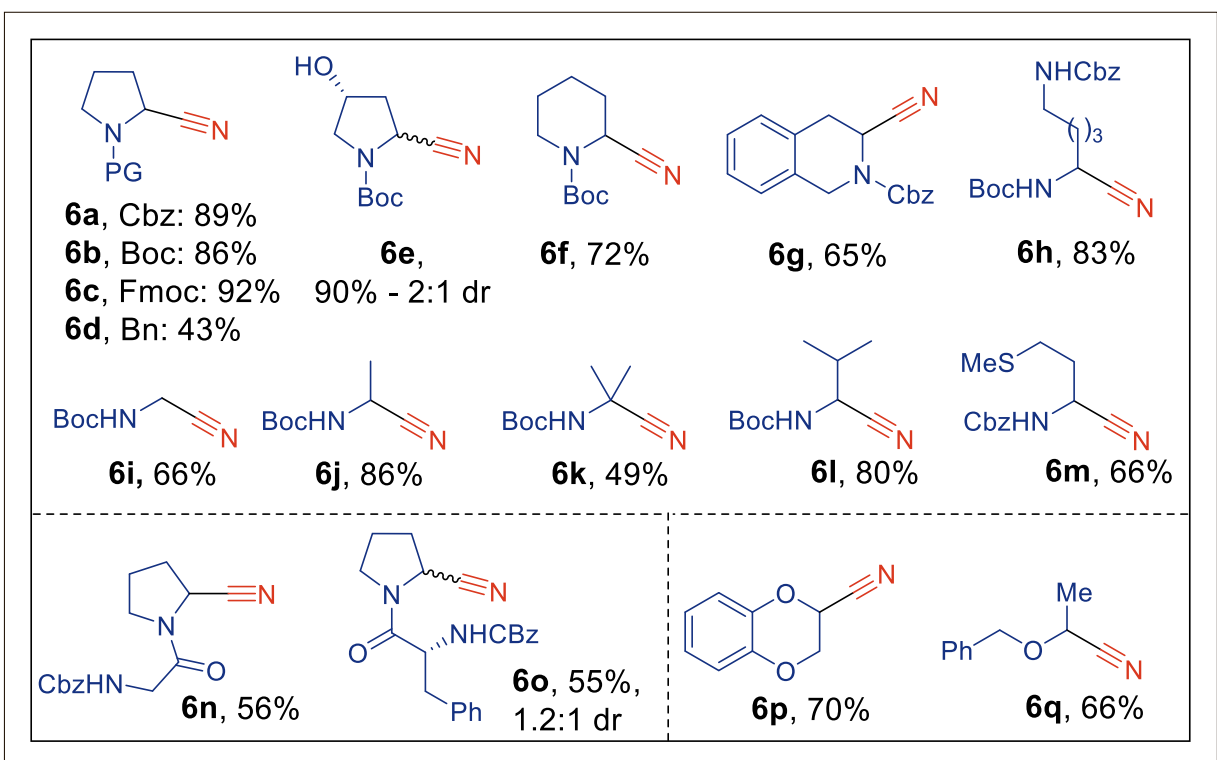

Fig. 3. Scope of the photoredox catalyzed decarboxylative cyanation. 
Table 1. Theoretically calculated energy in $\mathrm{kcal} / \mathrm{mol}$ of transition states in the alkynylation and cyanation

\begin{tabular}{|c|c|c|}
\hline & $\begin{array}{l}\text { Alkynylation } \\
\mathrm{X}=\mathrm{CSSi} \mathrm{Pr}_{3}\end{array}$ & $\begin{array}{l}\text { Cyanation } \\
X=N\end{array}$ \\
\hline Transition state $b_{\text {TS }}$ energy & 17.2 & 14.3 \\
\hline Transition state $\mathrm{c}_{\mathrm{TS}}$ energy & 16.8 & 16.3 \\
\hline Transition state $\mathrm{d}_{\mathrm{TS}}$ energy & 11.3 then 32.8 & 2.4 then 9.4 \\
\hline
\end{tabular}

be envisioned depending on the steric and electronics of the alkyne substituent.

On the other hand, CBX bears a more polarized functional group compared to TIPS-EBX. Cyclic voltammetry for CBX showed a reduction wave at $-0.92 \mathrm{~V}$ vs SCE, corresponding to an irreversible system, whereas no clear reduction wave was detected for TIPS-EBX. This means that $\mathrm{CBX}$ can further oxidize the $\alpha$-amino radical $\mathbf{B}$ generated in situ after the oxidation of the cesium carboxylate $\mathbf{A}$ and $\mathrm{CO}_{2}$ extrusion, leading to iminium intermediate $\mathbf{d}_{\mathbf{1}}$. The radical anion $[\mathbf{C B X}]^{\cdot-}$ would then collapse into nucleophilic cyanide $\mathbf{d}_{\mathbf{2}}$ and iodobenzoyl radical C. C can easily be reduced by strongly reducing $\mathbf{6}^{\text {red }}$, leading to cesium iodobenzoate $\mathbf{9}$ and regenerating the ground state of photocatalyst $\mathbf{3}$. Finally recombination of these two species via nucleophilic addition generates the corresponding nitrile $\mathbf{6}$. An isotopic experiment was performed using ${ }^{18} \mathrm{O}$ labelled water as additive. The corresponding labelled hemiaminal ${ }^{18} \mathrm{O}-7$ was found by mass spectrometry with $76 \%$ incorporation. This ionic pathway was also confirmed by DFT com- putations that showed the single electron transfer between CBX $\mathbf{2}$ and $\alpha$-amino radical $\mathbf{B}$ is the less energy demanding pathway $\left(2.4 \mathrm{kcal} / \mathrm{mol}\right.$ for $\mathbf{d}_{1}$ and $9.4 \mathrm{kcal} / \mathrm{mol}$ for $\mathbf{d}_{\mathbf{2}}$ ) compared to the $\alpha$-addition $\left(\mathbf{c}_{\mathrm{TS}}, 16.3\right.$ $\mathrm{kcal} / \mathrm{mol})$ and concerted mechanism $\left(\mathbf{b}_{\mathrm{TS}}\right.$, $14.3 \mathrm{kcal} / \mathrm{mol}) . \beta$-Addition would lead to stable isonitrile $\mathbf{c}_{2}(-23.1 \mathrm{kcal} / \mathrm{mol})$ that was not observed, therefore this pathway can also be excluded.

In summary, both one-step decarboxylative alkynylation and cyanation of aliphatic carboxylic acids were achieved through merging photoredox catalysis and cyclic hypervalent iodine reagents. The reactions proceed under very mild conditions, using 0.1 to $3.0 \mathrm{~mol} \%$ of $\operatorname{Ir}\left(\mathrm{dF}\left(\mathrm{CF}_{3}\right)\right.$ $\left.\mathrm{ppy}_{2}\right)_{\text {dtbbpyPF}}$ under visible light irradiation at room temperature. The divergent nature of the alknynylation and cyanation mechanisms was deduced using both experiment and theory. The alkyne transfer is a radical based mechanism, whereas an additional single electron transfer step generates ionic intermediates leading to a two electron pathway for the cyanide transfer.

\section{Acknowledgements}

We thank EPFL and European Research Council for financial support (ERC; Starting Grant iTools4MC, number 334840). The Laboratory for Computational Molecular Design at EPFL is acknowledged for providing computational resources.

Received: January 27, 2017

[1] For alkynes: a) B. M. Trost, C.-J. Li, 'Modern Alkyne Chemistry', Eds. B. M. Trost, C.-J. Li, Wiley-VCH, 2015; b) F. Diederich, P. J. Stang, R. R. Tykwinski, 'Acetylene Chemistry: Chemistry, Biology and Material Science', Eds. F. Diederich, P. J. Stang, R. R. Tykwinski, Wiley-VCH, 2005.

[2] For nitriles: a) Z. Rappoport, 'Chemistry of the Cyano Group', Wiley, London, 1970; b) F. F. Fleming, Nat. Prod. Rep. 1999, 16, 597; c) D. Enders, J. P. Shilvock, Chem. Soc. Rev. 2000, 29, 359; d) F. F. Fleming, Q. Z. Wang, Chem. Rev. 2003, 103, 2035; e) S. T. Murphy, H. L. Case, E. Ellsworth, S. Hagen, M. Huband, T. Joannides, C. Limberakis, K. R. Marotti, A. M. Ottolini, M. Rauckhorst, J. Starr, M. Stier, C. Taylor, T. Zhu, A. Blaser, W. A. Denny, G.-L. Lu, J. B. Smaill, F. Rivault, Bioorg. Med. Chem. Lett. 2007, 17, 2150; f) J. Kim, H. J. Kim, S. Chang, Angew. Chem., Int. Ed. 2012, 51, 11948; g) T. Wang, N. Jiao, Acc. Chem. Res. 2014, 47, 1137; h) Y. Ping, Q. Ding, Y. Peng, ACS Catal. 2016, 6, 5989.

[3] a) F. F. Fleming, L. Yao, P. C. Ravikumar, L. Funk, B. C. Shook, J. Med. Chem. 2010, 53, 7902; b) M. A. Perry, M. D. Morin, B. W. Slafer, S. D. Rychnovsky, J. Org. Chem. 2012 77, 3390.

[4] For alkynes: a) R. Chinchilla, C. Najera, Chem. Rev. 2007, 107, 874; b) R. Chinchilla, C. Najera, Chem. Soc. Rev. 2011, 40, 5084; c) For nitriles: D. T. Mowry, Chem. Rev. 1948, 42, 189.

[5] D. Seebach, Angew. Chem. Int. Ed., 1979, 18 , 239.

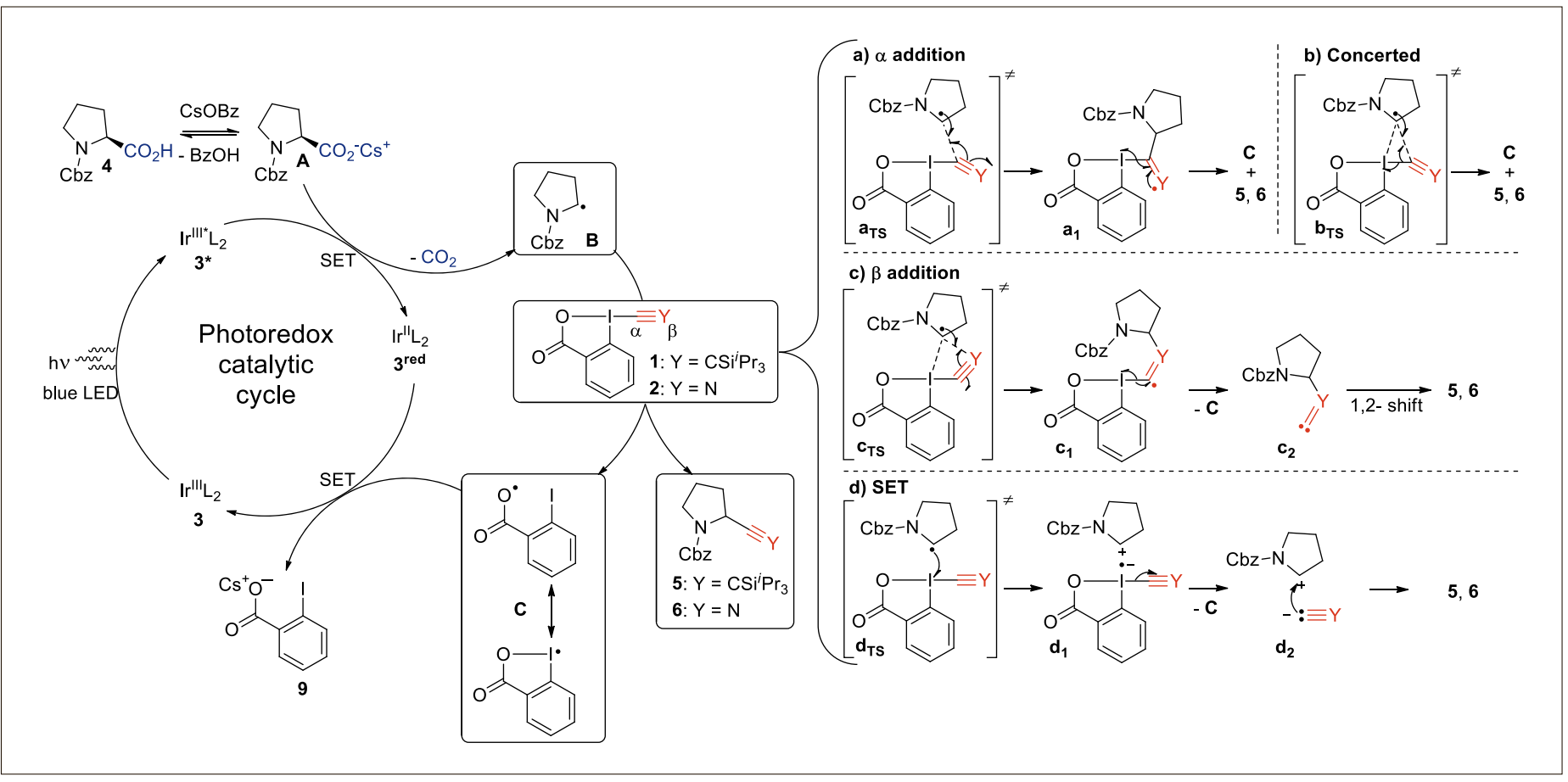

Scheme 3. Tentative mechanism for the photoredox catalyzed decarboxylative alkynylation and cyanation reactions. 
[6] M. Ochiai, Y. Masaki, M. Shiro, J. Org. Chem. 1991, 56. 5511.

[7] a) V. V. Zhdankin, C. J. Kuehl, A. P. Krasutsky, J. T. Bolz, A. J. Simonsen, J. Org. Chem. 1996 , 61, 6547; b) A. J. Simonsen, J. K. Woodward, B. Mismash, J. T. Bolz, A. P. Krasutsky, C. J. Kuehl, V. V. Zhdankin, Tetrahedron Lett. 1995, 36, 44, 7975 .

[8] For selected examples. a) J. P. Brand, J. Charpentier, J. Waser, Angew. Chem. Int. Ed. 2009, 48, 9346; b) R. Frei, T. Courant, M. D. Wodrich, J. Waser, Chem. Eur. J. 2015, 21, 2662. For reviews: c) J. Waser, Synlett 2016, 27, 2761; d) J. Waser, Top. Curr. Chem. 2015, 373, 187; e) Y. Li, D. P. Hari, M. V. Vita, J. Waser, Angew. Chem. Int. Ed. 2016, 55, 4436.

[9] For EBX reagents: a) X. Liu, Z. Wang, X. Cheng, C. Li, J. Am. Chem. Soc. 2012, 134, 14330; b) R.-Y. Zhang, L.-Y. Xi, L. Zhang, S. Liang, S.-Y. Chen, X.-Q. Yu, RSC Adv. 2014, 4, 54349; c) H. Huang, G. Zhang, Li Gong, S Zhang, Y. Chen, J. Am. Chem. Soc. 2014, 136, 2280.

[10] Selected examples and reviews: a) R. A. Shenvi, D. P. O'Malley, P. S. Baran, Acc. Chem. Res. 2009, 42, 530; b) D. A. Nicewicz, D. W. C. MacMillan, Science 2008, 322, 77; c) T. P. Yoon, M. A. Ischay, J. Du, Nat. Chem. 2010, 2, 527; d) J. M. R. Narayanam, C. R. J. Stephenson, Chem. Soc. Rev. 2011, 40, 102; e) J. W. Tucker, C. R. J. Stephenson, J. Org. Chem. 2012, 77, 1617; f) J. Xuan, W.-J. Xiao, Angew. Chem., Int. Ed. 2012, 51, 6828; g) C. K. Prier, D. A. Rankic, D. W. C. MacMillan, Chem. Rev.
2013, 113, 5322; h) D. M. Schultz, T. P. Yoon, Science 2014, 343, 985; i) D. Ravelli, S. Protti, M. Fagnoni, Chem. Rev. 2016, 116, 9850.

[11] J. Xuan, Z.-G. Zhang, W.-J. Xiao, Angew. Chem. Int. Ed. 2015, 54, 15632.

[12] a) H.-P. Bi, L. Zhao, Y.-M. Liang, C.-J. Li, Angew. Chem. 2009, 121, 806; b) H.-P. Bi, L. Zhao, Y.-M. Liang, C.-J. Li, Angew. Chem., Int. Ed. 2009, 48, 792; c) C. Zhang, D. Seidel, J. Am. Chem. Soc. 2010, 132, 1798; d) H.-P. Bi, Q. Teng, M. Guan, W.-W. Chen, Y.-M. Liang, X. Yao, C.-J. Li, J. Org. Chem 2010, 75, 783; e) Y.-S. Feng, Z.-Q. Xu, L. Mao, F.-F. Zhang, H.-J. $\mathrm{Xu}$, Org. Lett. 2013, 15, 1472.

[13] a) D. A. Klein, J. Org. Chem. 1971, 36, 3050; b) D. Cantillo, C. O. Kappe, J. Org. Chem. 2013, 78, 10567; c) D. Cartigny, A. Dos Santos, L. El Kaim, L. Grimaud, R. Jacquot, P. Marion, Synthesis 2014, 46, 1802; d) W. B. Motherwell, D. Crich, D. H. R. Barton, J. Chem. Soc. Chem. Commun. 1983, 939; e) E. Theodorakis, J. C. Jaszberenyi, D. H. R. Barton, Tetrahedron, 1992, 48, 2613

[14] a) F. Le Vaillant, T. Courant, J. Waser, Angew. Chem. Int. Ed. 2015, 54, 11200; b) Q.-Q. Zhou, W. Guo, W. Ding, X. Wu, X. Chen, L.-Q. Lu, W.-J. Xiao, Angew. Chem. Int. Ed. 2015, 54, 11196.

[15] See ref. [14a] for a full optimization table and comparison of photocatalysts performance.

[16] F. Le Vaillant, M. D. Wodrich, J. Waser, Chem. Sci. 2017, 8, 1790

[17] Oxidation potential of cesium hexanoate is +1.16 V vs SCE (M. Galicia, F. J. J. Gonzalez,
Electrochem. Soc. 2002, 149, D46), which is much higher than the one of N-Boc cesium prolinate $(+0.95 \mathrm{~V}$ vs SCE, Z. Zuo, D. W. C. MacMillan, J. Am. Chem. Soc. 2014, 136, 5257).

[18] L. Pellegatti, J. Sedelmeier, Org. Process Res. Dev. 2015, 19, 551.

[19] a) C. B. Chapleo, P. L. Myers, R. C. M. Butler, J. C. Doxey, A. G. Roach, C. F. C. Smith, J. Med. Chem. 1983, 26, 823; b) D. Giardina, P. Angeli, L. Brasili, U. Gulini, C. Melchiorre, G. Strappaghetti, Eur. J. Med. Chem. 1984, 19, 411.

[20] For both reactions, $\operatorname{Ir}\left(\mathrm{dF}\left(\mathrm{CF}_{3}\right) \mathrm{ppy}_{2}\right) \mathrm{dtbbpyPF}_{6}$ (3) is an efficient catalyst. When cheaper organic dyes such as 9,10-anthracenedicarbonitrile (DCA) and 9-mesityl-10methylacridinium perchlorate were used in the cyanation, no nitrile was obtained under the reaction conditions. In the alkynylation, DCA was efficient as described here: C. Yang, J.-D. Yang, Y.-H. Li, X. Li, J.-P. Cheng, J. Org. Chem. 2016, 81, 12357.

[21] Two reaction free energy profiles are available in ref. [16].

[22] Stern-Volmer studies are not available with TIPS-EBX and photocatalyst $\mathbf{3}$, but Cheng and coworkers showed that TIPS-EBX is not a quencher of DCA. (C. Yang, J.-D. Yang, Y.-H. Li, X. Li, J.-P. Cheng, J. Org. Chem., 2016, 81, 12357). 